\title{
Contextually enriched argument linking
}

\author{
Udo Klein*
}

March 28, 2012

\begin{abstract}
In this paper we investigate the role played by one aspect of context, namely encyclopedic knowledge, to the interpretation of clause arguments. We discuss cases where the assignment of a specific semantic role of a predicate to a clause argument is not determined by the grammar alone, but requires extragrammatical resources (in particular, world knowledge), and then present a formally explicit analysis of the interaction of grammar and world knowledge in the linking of clause arguments to specific semantic roles. The analysis of this interaction is based on the hypothesis that semantic composition consists in the identification of the referents introduced by NPs with the participants involved in the states of affairs described by predicates, with both referents and participants being represented by means of free variables. The contribution of the grammatical resources to the identification of free variables is captured by means of referent systems which essentially associate with each free variable the morphosyntactic information relevant for its identification. Two variables $x$ and $y$ can be identified (i.e. we can add the equation $x=y$ to the discourse representation structure) if they are associated with the same (or matching) information. The contribution of extragrammatical resources to the identification of free variables is modeled in terms of abductive reasoning based on encyclopedic knowledge.
\end{abstract}

\section{Introduction}

For an utterance $u$ to serve as an efficient means of communication, its interpretation needs to be (sufficiently) predictable from its formal structure,

*I would like to thank the audience at the DGFS 2011 workshop "What is a context? - Theoretical and experimental evidence", the organisers of the workshop, as well as two anonymous referees for thoughtful comments and suggestions. Thanks also to Marcus Kracht and Ralf Vogel for discussion and helpful suggestions. Of course, I take sole responsibility for all remaining errors. This research was conducted within the project A8 of the SFB674 "Alignment in Communication", whose financial support I thankfully acknowledge. 
but also (sufficiently) flexible to match different contexts of use and different background knowledge. Predictability is usually accounted for by postulating a systematic (compositional) relation between formal structure and linguistic meaning, while flexibility is accounted for by postulating that utterance interpretation results from enriching linguistic meaning in a variety of different ways. An open and currently hotly debated issue is how much context-dependent enrichment is necessary for mapping linguistic meaning into a truth-evaluable proposition. On the one hand Semantic Minimalism, as represented by Cappelen \& Lepore (2005), claims that only (a basic set of) indexicals is context-dependent, and that the resolution of indexicals generally determines a truth-evaluable proposition. On the other hand Contextualism, as represented by Recanati (2004), claims that many more expressions are context-sensitive, and that the resolution of (the basic set of) indexicals alone generally does not yield a truth-evaluable proposition.

An issue that has received comparatively little attention in this literature is the context-dependence of argument linking. Goldberg (1995: 43) distinguishes participant roles, which are specific semantic roles assigned by the verbs, from argument roles, which are generalized semantic roles assigned by constructions. An argument is then linked to a specific verb role by first linking the argument to an argument role, and then "fusing" this argument role with a participant role of a verb, with two roles being fused if they are simultaneously instantiated by one argument. Goldberg claims that there are two principles constraining fusion, namely the SEMANTIC COHERENCE PRINCIPLE, which requires that construction and verb roles are fused only if they are "semantically compatible", and the CORRESPONDENCE PRINCIPLE, which requires that profiled verb roles are fused with profiled construction roles. To illustrate, in (1):

Pat loaded the hay onto the truck.

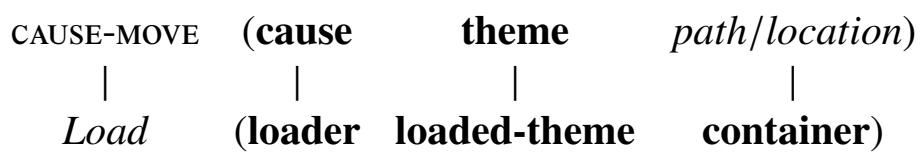

the loader can be construed as a cause, the loaded-theme argument can be construed as a type of theme, and the container argument can be construed as a path or location. Goldberg (2006: 36) acknowledges that "there is more to the interpretation of a clause than the argument structure construction used to express it", claiming that "[t]he overall interpretation is arrived at by integrating the argument structure construction with the main verb and various arguments, in light of the pragmatic context in which the clause is uttered." However, in her account the division of labor between formal structure and context in the determination of fusion is not made fully explicit. What exactly is the contribution of the formal structure to fusion? And what exactly is the 
contribution of utterance situation or conceptual/world knowledge to fusion?

In section 2 we discuss cases where the assignment of a specific semantic role of a predicate to a clause argument is not determined by the grammar alone but requires extragrammatical resources, in particular inferences based on world knowledge. We then present a formally explicit analysis of the interaction of grammar and encyclopedic knowledge in the linking of clause arguments to specific semantic roles. The analysis of this interaction is based on the hypothesis that semantic composition consists in the identification of the referents introduced by NPs with the participants involved in the states of affairs described by predicates, with both referents and participants being represented by means of free variables. The contribution of the grammatical resources to the identification of free variables is captured by means of referent systems which essentially associate with each free variable the morphosyntactic information relevant for its identification. Two variables $x$ and $y$ can be identified (i.e. the equation $x=y$ can be added to the discourse representation structure) if they are associated with the same (or matching) information. This will be developed in section 3. The contribution of extragrammatical resources to the identification of free variables is modeled in section 4 in terms of abductive reasoning based on encyclopedic knowledge. Section 5 concludes.

\section{Contextually enriched argument linking}

The interpretation of an utterance of Pat injured Pete. includes understanding (i) what kind of state of affairs (or eventuality) the verb injured describes and (ii) how the persons named Pat and Pete are involved in this state of affairs. An entity involved in a state of affairs will be called a participant (in this state of affairs). Participants can be involved in states of affairs or eventualities in different ways - they can play different roles in it. The roles that participants in a state of affairs $s$ can play will be called the specific semantic roles of $s$. If in a state of affairs $s$ the participants can play the specific semantic roles $r_{1}, \ldots, r_{n}$, we say that the state $s$ assigns the roles $r_{1}, \ldots, r_{n}$. If a participant $p$ actually plays the role $r$ in a state of affairs $s$, we say that $p$ is assigned the semantic role $r$ of $s$. If a participant $p$ is assigned the semantic role $r$ of a state of affairs (or eventuality) $s$, we say that $p$ has been linked to $s$. We assume that the participants involved in a particular way in a state of affairs are uniquely determined. ${ }^{1}$ If in an injuring event $e$ Pete is the person injured, the principle of uniqueness of participants (UP) excludes any entities other than Pete from being entities injured in $e$. If in a complex injuring event $e^{\prime}$ both Pete and Mary are entities injured, then the up excludes any entities different from Pete and Mary from being injured in $e^{\prime}$.

\footnotetext{
${ }^{1}$ Cf. Krifka (1998).
} 
One of the central tasks of interpretation is to determine how entities relate to states of affairs. The entities denoted by the clause arguments need to be linked to the state of affairs denoted by the clause predicate (i.e. they need to be assigned some specific semantic role). This process, called argument linking, is determined to a large part by the grammar. In this section we will discuss examples showing that the assignment of specific roles to the clause arguments depends not only on grammatical but also on extragrammatical knowledge. To begin with, consider the following sentences: ${ }^{2}$
a. Ein Ball rollte in die Schlucht.
'A ball rolled into the ravine.'
b. $\quad$ Ein Auto rollte in die Schlucht.
'A car rolled into the ravine.'

By default, a ball involved in a rolling event is interpreted as rotating along its own axis, whereas a car involved in a rolling event is not interpreted as rotating along its own axis. This difference in interpretation can be analyzed in at least two different ways. The first is to assume that rollen is ambiguous, with the first sense being that $x$ moves by rotating along its own axis, and the second sense being that $x$ moves by having wheels that rotate along their own axes. The choice of the appropriate sense then determines the specific semantic role of the subject denotation: choosing the first sense in (2-a) assigns to the denotation of the subject (some ball) the specific role of entity moving by rotating along its own axis, whereas choosing the second sense in (2-b) assigns to the denotation of the subject (some car) the role of entity moving by having its wheels rotate along their axes. The choice of the appropriate sense of rollen is, however, not determined by the grammar. If we knew everything about German grammar but nothing about balls or cars we would not be able to choose the appropriate sense of rollen.

To illustrate the point that these interpretations are default interpretations, consider the following report of an accident: ${ }^{3}$
Der Fiat [...] überschlug sich und rollte auf ein Feld hinunter, wo er mit den Rädern nach oben liegenblieb.( Source: TAZ 1990 )
'The Fiat overturned and rolled down onto a field, where it came to a standstill with the wheels upward.'

That the car overturned and came to a standstill with its wheels upwards implies that the car itself was rotating as it rolled down onto the field. The coherent interpretation of (3), and thus the choice of the appropriate sense of rollen, makes use of the world knowledge that if cars move downhill by

\footnotetext{
${ }^{2}$ See Vogel (1998) for an extensive discussion of rollen and other polyvalent verbs.

${ }^{3}$ Found with Google Search on http : //www . mydict . com/Wort/überschlug/Page/7/, 30.01.2012.
} 
rotating along their own axis they may come to a standstill with their wheels up.

The second way in which this difference in default interpretation could be analyzed is (i) to assume only one meaning for the verb rollte in (2), namely that $x$ is moving by rotating along its own axis, and (ii) to assume that this meaning can be contextually enriched in different ways depending on the subject denotation and on our world knowledge. Both analyses will be carried out in detail in section 3 .

While under the ambiguity analysis the assignment of specific roles in the previous examples depends on which sense of an ambiguous lexical item is chosen, the assignment of specific roles may also depend on the choice of construction, as illustrated below:

$$
\begin{aligned}
& \text { a. ein Blatt zu einem Papierflieger falten } \\
& \text { a sheet to a paper plane fold } \\
& \text { 'fold a sheet into a paper plane' } \\
& \text { b. ein Foto zu einem Trapez verzerren } \\
& \text { a photo to a trapezoid distort } \\
& \text { 'distort a photo into a trapezoid' }
\end{aligned}
$$
a. ein Blatt falten
'fold a sheet'
b. ein Flugzeug falten
'fold a paperplane'
a. ein Foto verzerren 'distort a photo'
b. \#ein Trapez verzerren INT.: 'distort a trapezoid' (trapezoid=output)

The sentences in (5) show that the interpretation of the direct object of falten is flexible in the sense that the direct object denotation can be either the input or the output of the folding process. The contrast in (6), however, shows that the interpretation of the direct object of verzerren is not equally flexible: the direct object denotation can only be the input to the distortion process, not the output.

A number of other verbs display the same input/output ambiguity in the interpretation of the direct object, making it theoretically unattractive to postulate that each of these verbs is systematically polysemous:
a. Sand / ein Loch schaufeln 'shovel sand /a hole'
b. die Bücher / einen Turm stapeln 'pile the books / a tower'
c. einen Reifen / eine Zigarette rollen 


\section{'roll a tyre / a cigarette' \\ d. einen Ball / ein Tor werfen \\ 'throw a ball / score a goal' 4}

Put differently, this generalization can be captured by postulating a construction or lexical rule, which adds the information that as a result of the event described by the verb an object has been created. In most cases there is only one coherent way of interpreting the direct object. In some cases, however, both ways of interpreting the direct object are coherent (8), so that the interpretation depends on whether or not the creation rule/construction has applied to the verb. And this, in turn is again dependent on extragrammatical knowledge, as shown e.g. by (8-a), which may be interpreted either as saying that as the result of folding something an envelope has been created, or that an envelope (existing prior to the folding event) has been folded.
a. einen Umschlag falten
'fold an envelope'
b. eine Zigarette rollen
'roll a cigarette'

In all cases so far, the dependence of specific role assignment on extragrammatical knowledge could be reduced to the choice of lexical item or construction being dependent on extragrammatical knowledge. This strategy has its limits, however, as the following examples illustrate. ${ }^{5}$
a. einen Ball ins Tor werfen
'throw a ball into the goal'
b. ein Loch ins Tor werfen
'throw a hole into the goal'
a. einen Nagel in die Wand schlagen
'hit a nail into the wall'
b. einen Hammer in die Wand schlagen
'hit a hammer into the wall'
c. ein Loch in die Wand schlagen
'hit a hole into the wall'

While the direct object in (9-a) is interpreted as the entity thrown, the direct object in (9-b) cannot be interpreted as the entity thrown. But this difference in the interpretation of the direct object cannot plausibly be accounted for in terms of different lexical entries for werfen. Neither is it plausible to assume that the grammatical structure of (9-a) and (9-b) differ.

By default, the interpretation of $(10-a)$ is that some instrument is hit against

\footnotetext{
${ }^{4}$ Incidentally, English does not allow the direct object of throw to be interpreted flexibly.

${ }^{5}$ The observation about the polyvalency of schlagen goes back to Vogel (1998).
} 
a nail, and as a consequence the nail comes to be in the wall. Again by default, the interpretation of (10-b) is that the hammer is hit against the wall, and as a consequence the hammer comes to be in the wall. The interpretation of (10-c) is that as a consequence of some instrument being hit against the wall, a hole comes to be in the wall. As with the examples in (9), it is neither plausible to assume different lexical entries for schlagen, nor is it plausible to assume structural differences between the sentences in (10). Consequently, the dependence of the direct object interpretation on extragrammatical knowledge cannot be analyzed in terms of the choice of different lexical items or different constructions being dependent on extragrammatical knowledge. These examples thus illustrate that the assignment of specific semantic roles to clause arguments is not fully determined by the grammar (and the choice of lexical items), but requires extragrammatical knowledge.

In the following sections we provide a formal analysis of the interaction between grammatical and extragrammatical resources in the assignment of specific semantic roles to clause arguments. The participants involved in a state of affairs described by a verb as well as the referents introduced by noun phrases will be represented by means of free variables. Semantic composition essentially boils down to identifying free variables. Free variables are identified by using both grammatical and extragrammatical resources. The contribution of the grammatical resources to the identification of free variables is captured by means of referent systems which essentially associate with each free variable the morphosyntactic information relevant for its identification. Two variables $x$ and $y$ can be identified (i.e. we can add the equation $x=y$ to the discourse representation structure) if they are associated with the same (or matching) information. This will be developed in the next section. The contribution of extragrammatical resources to the identification of free variables is modeled in terms of abductive enrichment based on encyclopedic knowledge. If, for example, a discourse representation structure contains the information that $x$ is the entity targeted in a hitting event, and we can add by abductive reasoning the assumption that some nail $y$ is the entity targeted in same hitting event, then $x$ and $y$ are identified, since by the principle of the uniqueness of participants the (singular or plural) entity hit in a hitting event is uniquely determined.

\section{Semantic composition with referent systems}

In this section we develop the idea of semantic composition by identification of free variables. First we introduce the basic idea. Then we discuss the role of construal in semantic composition. And finally we provide an analysis of the semantic composition involved in some examples discussed in the previous section. 


\subsection{The basic idea}

Consider the following sentence:
Ein
Hund jagt einen
Kater.
a:MASC:SG:NOM dog chases a:MASC:SG:ACC tomcat 'A dog chased a tomcat.'

Let us assume that (i) the NP ein Hund contributes a discourse referent $x$ satisfying the conditions of being a dog and being a new discourse referent relative to the context of interpretation, ${ }^{6}$ that (ii) the NP einen Kater contributes a discourse referent $y$ satisfying the conditions of being a tomcat and being a new discourse referent relative to the context of interpretation, and that (iii) jagt contributes an event of chasing involving two participants $u$ and $v$, with $u$ being the entity chasing and $v$ the entity chased. Instead of classical DRT's procedural approach to the computation of DRSs (Kamp \& Reyle, 1993), here we choose the algebraic approach to the computation of DRSs (Zeevat, 1989), where the lexical items themselves are associated with DRSs (instead of being associated with procedures for changing DRSs).

Given these assumptions, semantic composition can be achieved by means of identification of referents, represented by means of free variables. ${ }^{7}$ The composition of ein Hund and jagt should result in the identification of the discourse referent $x$ introduced by ein Hund with the entity $u$ participating as the entity chasing in the chasing event introduced by the verb (see figure 1). The composition of ein Hund jagt with einen Kater should result in the iden-

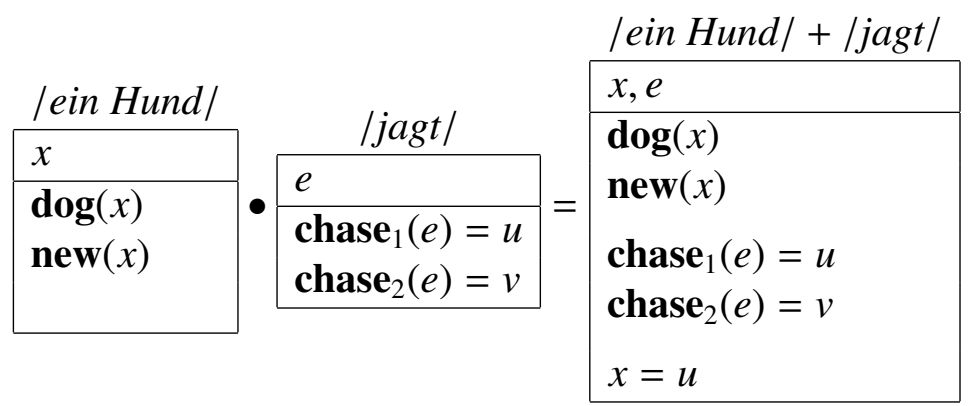

Figure 1: Desired composition of ein Hund with jagt

tification of the discourse referent $y$ introduced by einen Kater with the entity $v$ participating as the chased entity in the chasing event (figure 2). The identification of variables is steered by morphosyntactic information. The idea is that each variable is associated with a label containing morphosyntactic information, and that two variables can be identified if their labels match.

\footnotetext{
${ }^{6}$ If $U$ is the universe of discourse, let new $(x)$ be true iff $x \notin U$.

${ }^{7}$ See Klein (2012) for a proposal on how to treat generalized quantifiers in this framework.
} 


\begin{tabular}{|c|c|c|c|}
\hline \multirow[b]{3}{*}{ /ein Hund/ + /jagt/ } & \multirow{4}{*}{ /einen Kater/ } & & /ein Hund/ + /jagt/ + /einen Kater/ \\
\hline & & & $x, e, y$ \\
\hline & & & $\operatorname{dog}(x)$ \\
\hline$x, e$ & & & new $(x)$ \\
\hline $\operatorname{dog}(x)$ & $y$ & & $\operatorname{chase}_{1}(e)=u$ \\
\hline $\operatorname{new}(x)$ & - tomcat $(y)$ & $=$ & $\operatorname{chase}_{2}(e)=v$ \\
\hline $\begin{array}{l}\operatorname{chase}_{1}(e)=u \\
\operatorname{chase}_{2}(e)=v\end{array}$ & $\operatorname{new}(y)$ & & $x=u$ \\
\hline & & & $\begin{array}{l}\operatorname{tomcat}(y) \\
\operatorname{new}(y)\end{array}$ \\
\hline & & & $y=v$ \\
\hline
\end{tabular}

Figure 2: Composing ein Hund jagt with einen Kater.

To illustrate, assume that (i) the variables $u$ and $v$ of jagt are associated with nominative ([CASE : nom]) and accusative case ([CASE : acc]), respectively, (ii) the variable $x$ of ein Hund is associated with nominative case, and that the variable $y$ of einen Kater is associated with accusative case. Then $x$ can be identified with $u$ since both variables are associated with nominative case, while $y$ identifies with $v$ since they are associated with accusative case (figure 3). Importantly, the identification of variables is determined by matching

\begin{tabular}{|c|c|c|}
\hline /ein Hund/ & \multirow{3}{*}{$\begin{array}{c}\text { /jagt/ } \\
u:[\text { CASE }: \text { nom }] \\
v:[\text { CASE }: \text { acc }]\end{array}$} & $\begin{array}{l}\text { /ein Hund/ + /jagt/ } \\
u:[\text { CASE }: \text { nom] } \\
v:[\text { CASE }: \text { acc }]\end{array}$ \\
\hline$x:[$ CASE $:$ nom] & & 2 \\
\hline$x$ & & $\operatorname{dog}(x)$ \\
\hline $\operatorname{dog}(x)$ & $e$ & new $(x)$ \\
\hline $\operatorname{new}(x)$ & $\begin{array}{l}\operatorname{chase}_{1}(e)=u \\
\operatorname{chase}_{2}(e)=v\end{array}$ & $\operatorname{chase}_{1}(e)=u$ \\
\hline & & $x=u$ \\
\hline
\end{tabular}

Figure 3: Associating referent with morphosyntactic information.

morphosyntactic information, and not by the actual variable name chosen to represent the referent. Intuitively, the variable chosen to represent the discourse referent introduced by ein Hund does not actually matter - what matters is only that the discourse referent be a dog and that it be discourse-new. Therefore, the mechanics of variable identification should function appropriately irrespective of whether we chose $x, y$ or $z$ to represent this discourse 
referent. But consider what happens if instead of $y$ as a variable name for the referent introduced by einen Kater we choose $x$. First we assign $x$ to a tomcat that is a new discourse referent (the semantic contribution of einen Kater), and then we merge with the DRS for ein Hund jagt (figure 4). The inciden-

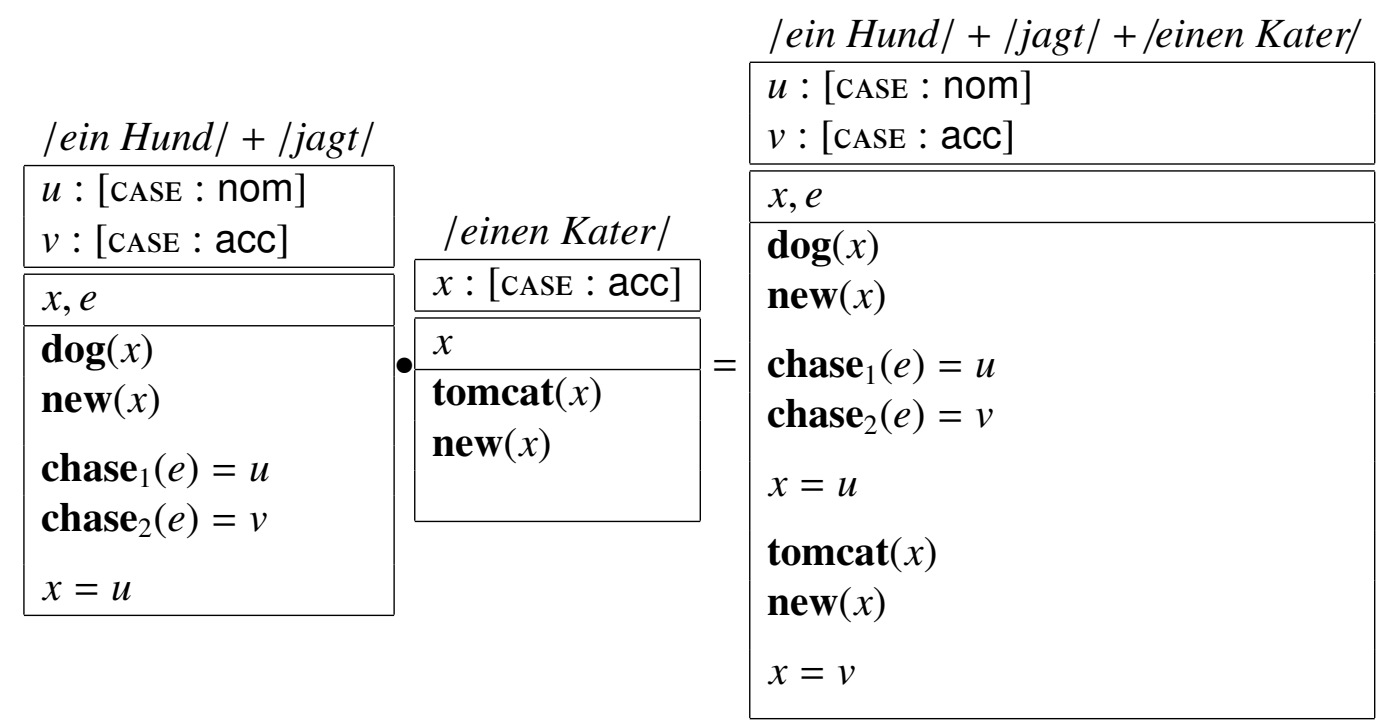

Figure 4: Composing accusative direct object.

tal use of $x$ as a name for the referent introduced by einen Kater leads to an unwanted identification with the referent introduced by ein Hund. In classical DRT accidental identifications of this kind do not occur, because the semantic contribution of the indefinite NPs is expressed in a procedural way ('introduce a new referent'). In our declarative approach this accidental identification of variables can be avoided by formulating the merge operation such that in the resulting DRS the variables from the left DRS are suffixed with the integer 1 and the variables from the right DRS are suffixed with the integer 2 (figure 6).

In addition to the morphosyntactic information encoded in the label of the referent, the identification of variables depends also on matching diacritics. Hierarchical information is encoded by the following (vertical) diacritics: (i) $\nabla$ (the referent is a functor with respect to merge) (ii) $\Delta$ (the referent is an argument with respect to merge), (iii) $\diamond$ (the referent is an adjunct), and (iv) - (the referent cannot identify any further). Linear information is encoded by the following (horizontal) diacritics: (i) $\oslash$ (referent expects argument to the right), (ii) $\diamond$ (referent expects argument to the left), (iii) $\oplus$ (referent expects argument either to the left or to the right), and (iv) $\bigcirc$ (no expectations).

A tuple containing a variable, vertical and horizontal diacritics and a label is called an argument identification statement (AIS). A sequence of argument 


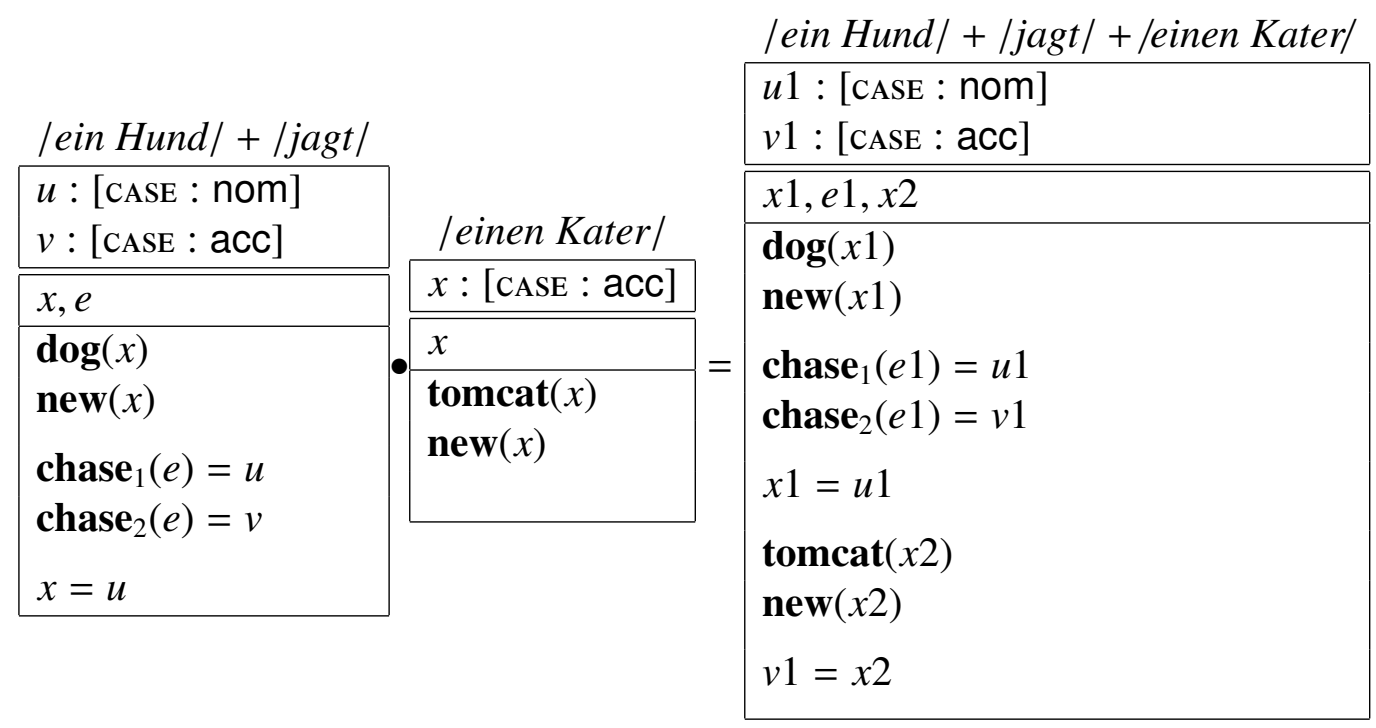

Figure 5: Renaming of free variables during merge.

identification statements is called a referent system. ${ }^{8}$ The AIS for ein Hund is represented as $x: \triangle \mathrm{O}:$ [CASE : nom]. The corresponding AIS of the verb is $x: \nabla \Phi:$ [CASE : nom].

The rightward merge of argument identification statements (meaning that the right AIS is argument and the left AIS is functor) is illustrated ${ }^{9}$ in figure 6. The main condition on the merge of AISs is that the two labels (which are sets of attribute-value pairs) can be unified. The leftward merge of argument

\begin{tabular}{l|l|l|l} 
left AIS & right AIS & result of rightward merge & condition \\
\hline$x: \nabla \oplus: L_{1}$ & $y: \triangle \bigcirc: L_{2}$ & $x 1:-\oplus: L_{1} \sqcap L_{2}$ & if $L_{1} \sqcap L_{2}$ is defined \\
$x: \nabla \otimes: L_{1}$ & $y: \Delta \bigcirc: L_{2}$ & $x 1:-\oplus: L_{1} \sqcap L_{2}$ & if $L_{1} \sqcap L_{2}$ is defined \\
$x: \diamond Ф: L_{1}$ & $y: \Delta \bigcirc: L_{2}$ & $x 1: \triangle \bigcirc: L_{1} \sqcap L_{2}$ & if $L_{1} \sqcap L_{2}$ is defined \\
$x: \diamond \otimes: L_{1}$ & $y: \triangle \bigcirc: L_{2}$ & $x 1: \triangle \bigcirc: L_{1} \sqcap L_{2}$ & if $L_{1} \sqcap L_{2}$ is defined
\end{tabular}

Figure 6: Rightward merge of argument identification statements.

identification statements (meaning that the left AIS is argument and the right AIS is functor) is displayed in figure 7. The rightward (leftward) merge of referent systems is defined if there is at least one pair of AISs that can rightward (leftward) merge. The rightward (leftward) merge of referent systems

\footnotetext{
${ }^{8}$ The calculus of referent systems was first introduced in Vermeulen (1995) and then considerably extended in Kracht (1999).

${ }^{9}$ See appendix A for the definition.
} 


\begin{tabular}{l|l|l|l} 
left AIS & right AIS & result of leftward merge & condition \\
\hline$y: \triangle \bigcirc: L_{2}$ & $x: \nabla \oplus: L_{1}$ & $x 1:-\oplus: L_{1} \sqcap L_{2}$ & if $L_{1} \sqcap L_{2}$ is defined \\
$y: \triangle \bigcirc: L_{2}$ & $x: \nabla \otimes: L_{1}$ & $x 1:-\oplus: L_{1} \sqcap L_{2}$ & if $L_{1} \sqcap L_{2}$ is defined \\
$y: \triangle \bigcirc: L_{2}$ & $x: \diamond Ф: L_{1}$ & $x 1: \triangle \bigcirc: L_{1} \sqcap L_{2}$ & if $L_{1} \sqcap L_{2}$ is defined \\
$y: \triangle \bigcirc: L_{2}$ & $x: \diamond \diamond: L_{1}$ & $x 1: \triangle \bigcirc: L_{1} \sqcap L_{2}$ & if $L_{1} \sqcap L_{2}$ is defined
\end{tabular}

Figure 7: Leftward merge of argument identification statements.

requires that the right referent system be saturated, i.e. that it may contain no AIS with $\nabla$ or $\diamond$ as a vertical diacritic. The fusion of referent systems does not impose this restriction, so that both referent systems can contain AISs with $\nabla$ or $\diamond$ as a vertical diacritic.

\subsection{Semantic composition and construal}

The rules of semantic composition are unlikely to refer directly to specific semantic roles: (i) this would require as many rules as there are specific semantic roles (ways in which entities can be involved in states of affairs), (ii) in many cases this would obscure why the participants receiving different roles have similar morphosyntactic properties, and (iii) the addition of a predicate involving new specific semantic roles would require adding new rules of semantic composition. Therefore, semantic composition rules link participants and states of affairs not by referring to specific semantic roles directly, but by referring to the construal of the state of affairs, i.e. to the way in which it is conceptualized.

One option would be to assume that the specific semantic roles of a state of affairs are (partially) ordered. Semantic composition rules could then refer to this (partial) ordering of specific semantic roles, so that the specific semantic roles themselves are irrelevant for semantic composition - what matters for the rule is which one is "first", "second", etc. This presupposes that states are essentially analyzed in terms of sets of tuples (i.e. relations). This is what the ordering convention in predicate logic amounts to. A second option would be to assume that instead of being partially ordered, specific semantic roles are classified into generalized semantic roles (Dowty, 1991), so that the rules of semantic composition refer to these generalized semantic roles and not to the specific roles directly. And thirdly, one could assume that the specific semantic roles are identified by their positions in the hierarchical structure of the representations of states of affairs, so that semantic composition rules refer to this position in hierarchical structure. Levin \& Rappaport Hovav (2005) provides an excellent survey of such theories of argument linking. This essentially presupposes that the semantic rules refer to properties of the repre- 
sentation of an event or state, as opposed to the properties of the event or state itself. All three options need to specify the principles by which the specific semantic roles are related to (partial) ordering, generalized role or hierarchical structure.

We propose a distinction between two levels of construal: at the higher, more abstract, level referents are construed in one of three different ways, namely (i) as prominent (or designated), represented by means of [csL : prom], (ii) as oblique ([CSL : obl]), or (iii) as structural ([CSL : struc]). To illustrate, the entities participating in selling event (the person selling, the person buying, the item) are construed as prominent, structural and oblique, respectively. ${ }^{10}$ On a lower less abstract level, the same entity may be construed in different ways: e.g. the person selling in a transaction event may be construed either as an actor (if the transaction is described by means of the verb sell) or as a source (if the transaction is described by means of buy).

Continuing with the analysis of (11), the verb jagt construes the entity chasing as the prominent entity and the entity chased as a structural entity. The transitive construction (TC) (i) checks that the verb is finite $(f: \diamond \mathbb{D}$ : [CAT : vfin]), (ii) trades in the construal of the designated argument $(x: \nabla \oplus$ : [CSL : prom]) for the nominative case $\left(x^{\prime}: \nabla \Phi:\right.$ [CASE : nom] and $\left.x=x^{\prime}\right)$, (iii) trades in the construal of the structural argument $(z: \nabla \oplus:$ [CSL : struc]) for the accusative case $\left(z^{\prime}: \nabla \Phi:\right.$ [CASE : acc] and $\left.z=z^{\prime}\right)$, and (iv) specifies that the arguments $x^{\prime}$ and $z^{\prime}$ are instigator and theme of the event $f$, respectively.

The semantic composition of jagt and the transitive construction, illustrated in figure 8, proceeds by identifying the referents $e, x, y$ of jagt with the referents $e, x, y$ of Tc, respectively. The AIS $e: \diamond \Phi:$ [CAT : vfin] of the transitive construction merges to the left with the AIS $e: \Delta \mathrm{O}:$ [CAT : vfin] of jagt, resulting in $e: \triangle \mathrm{O}:$ [CAT : vfin], and thus ensures that the verb combining is finite. where the resulting structure can be represented in simplified form as illustrated in figure 9.

\subsection{Semantic composition via referent systems}

As argued in section 2, there are at least two different ways of analyzing the difference in interpretation in (2). Assuming that rollte is polysemous, we can postulate the lexical entries in figure 10. The difference between the two senses is that rollte ${ }_{1}$ construes the entity rotating along its own axis as a structural entity, whereas rollte $_{2}$ construes the entity whose wheels are rotating

\footnotetext{
${ }^{10}$ Unaccusative verbs like ankommen ('arrive') construe their argument as structural, while unergative verbs like tanzen construe their argument as prominent. Assuming further that the passive auxiliaries can only combine with past participles that construe an argument as prominent then explains why es wurde getanzt ('it was danced') is grammatical, whereas es wurde angekommen ('it was arrived') is not. Cf. Haider (1986) for an analysis of the German passive in these terms.
} 


\begin{tabular}{|c|c|c|c|}
\hline & & $\mid$ jagt $\mid+\mathrm{TR}$ \\
\hline & TR & & $e: \triangle O:[\mathrm{CAT}: \mathrm{vfin}]$ \\
\hline & $e: \diamond \Phi:[$ CAT $:$ vfin] & & $x:-\bigcirc:[\mathrm{CSL}:$ prom] \\
\hline |jagt/ & $x: \nabla \oplus:[\mathrm{cSL}:$ prom $]$ & & $y:-\bigcirc:[$ CSL : struc] \\
\hline$e: \triangle \mathrm{O}:[\mathrm{CAT}: \mathrm{vfin}]$ & $y: \nabla \oplus:[\mathrm{csL}:$ struc $]$ & & $x^{\prime}: \nabla \Phi:[$ CASE $:$ nom] \\
\hline$x: \triangle O:[\mathrm{csL}:$ prom $]$ & $x^{\prime}: \nabla \oplus:[\mathrm{CASE}: \mathrm{nom}]$ & & $y^{\prime}: \nabla \oplus:[$ CASE $:$ acc $]$ \\
\hline$y: \Delta O:[\mathrm{CSL}:$ struc] & $y^{\prime}: \nabla \oplus:[\mathrm{CASE}: \mathrm{acc}]$ & $=$ & $e$ \\
\hline$e$ & $e$ & & $\operatorname{chase}_{1}(e)=x$ \\
\hline $\operatorname{chase}_{1}(e)=x$ & $\operatorname{instigator}\left(e, x^{\prime}\right)$ & & $\operatorname{chase}_{2}(e)=y$ \\
\hline $\operatorname{chase}_{2}(e)=y$ & theme $\left(e, y^{\prime}\right)$ & & $\operatorname{instigator}\left(e, x^{\prime}\right)$ \\
\hline & $\begin{array}{l}x=x^{\prime} \\
y=y^{\prime}\end{array}$ & & $\begin{array}{l}\text { theme }\left(e, y^{\prime}\right) \\
x=x^{\prime}\end{array}$ \\
\hline & & & $y=y^{\prime}$ \\
\hline
\end{tabular}

Figure 8: Combining jagt with Tc.

\begin{tabular}{|c|c|c|}
\hline $\mid$ jagt $\mid+\mathrm{TR}$ & & \\
\hline$e: \triangle O:[\mathrm{CAT}: \mathrm{vfin}]$ & \multirow{9}{*}{$\leftrightarrow$} & \\
\hline$x:-\bigcirc:[$ csL : prom $]$ & & $\mid$ jagt $\mid+\mathrm{TR}$ \\
\hline$y:-\bigcirc:[$ csL : struc $]$ & & $e: \triangle \mathrm{O}:[\mathrm{CAT}: \mathrm{vfin}]$ \\
\hline$x^{\prime}: \nabla \Phi:[$ CASE $:$ nom $]$ & & $x: \nabla \emptyset:[$ CASE $:$ nom] \\
\hline$y^{\prime}: \nabla \emptyset:[\operatorname{case}:$ acc $]$ & & $y: \nabla \oplus:[\mathrm{CASE}: \mathrm{acc}]$ \\
\hline$e$ & & $e$ \\
\hline $\begin{array}{l}\operatorname{chase}_{1}(e)=x \\
\operatorname{chase}_{2}(e)=y\end{array}$ & & $\begin{array}{l}\operatorname{chase}_{1}(e)=x \\
\operatorname{chase}_{2}(e)=y\end{array}$ \\
\hline $\begin{array}{l}\operatorname{instigator}\left(e, x^{\prime}\right) \\
\text { theme }\left(e, y^{\prime}\right)\end{array}$ & & $\begin{array}{l}\operatorname{instigator}(e, x) \\
\text { theme }(e, v)\end{array}$ \\
\hline $\begin{array}{l}x=x^{\prime} \\
y=y^{\prime}\end{array}$ & & \\
\hline
\end{tabular}

Figure 9: Simplified representation.

along their own axes as a structural entity. The intransitive construction essentially assigns nominative case to an entity construed as prominent or structural and additionally imposes the condition that at a lower level the entity be construed as a figure. ${ }^{11}$ Combining / rollte $_{1} /$ with ITR identifies the entity rolling with the entity being assigned nominative case, as illustrated in figure 11.

\footnotetext{
${ }^{11}$ According to Langacker (1987: 120), "the figure within a scene is a substructure perceived as "standing out" from the remainder (the ground) and accorded special prominence as the pivotal entity around which the scene is organized" (emphasis in original, UK).
} 


\begin{tabular}{|c|c|c|}
\hline /rollte $_{1} /$ & $/$ rollte $_{2} /$ & ITR \\
\hline$e: \triangle \mathrm{O}:[\mathrm{CAT}: \mathrm{vfin}]$ & $e: \triangle \mathrm{O}:[\mathrm{cAT}: \mathrm{vfin}]$ & \multirow{3}{*}{$\begin{array}{l}e: \diamond \Phi:[\text { CAT }: \text { vfin }] \\
x: \nabla \Phi:[\text { CSL }: \text { struc } \vee \text { prom }] \\
y: \nabla \Phi:[\text { CASE }: \text { nom }]\end{array}$} \\
\hline$x: \Delta O:[$ CSL : struc $]$ & $x: \Delta O:[$ csL $:$ struc $]$ & \\
\hline$e$ & $e$ & \\
\hline $\operatorname{roll}(e)=x$ & \multirow{2}{*}{$\begin{array}{l}\operatorname{roll}(e)=y \\
\text { wheels }(x)=y\end{array}$} & \multirow{2}{*}{$\begin{array}{l}\text { figure }(e, y) \\
x=y\end{array}$} \\
\hline & & \\
\hline
\end{tabular}

Figure 10: Two entries for rollte and the intransitive construction.

Combining /ein Ball/ with / rollte $_{1} /+$ ITR assigns the referent introduced by the

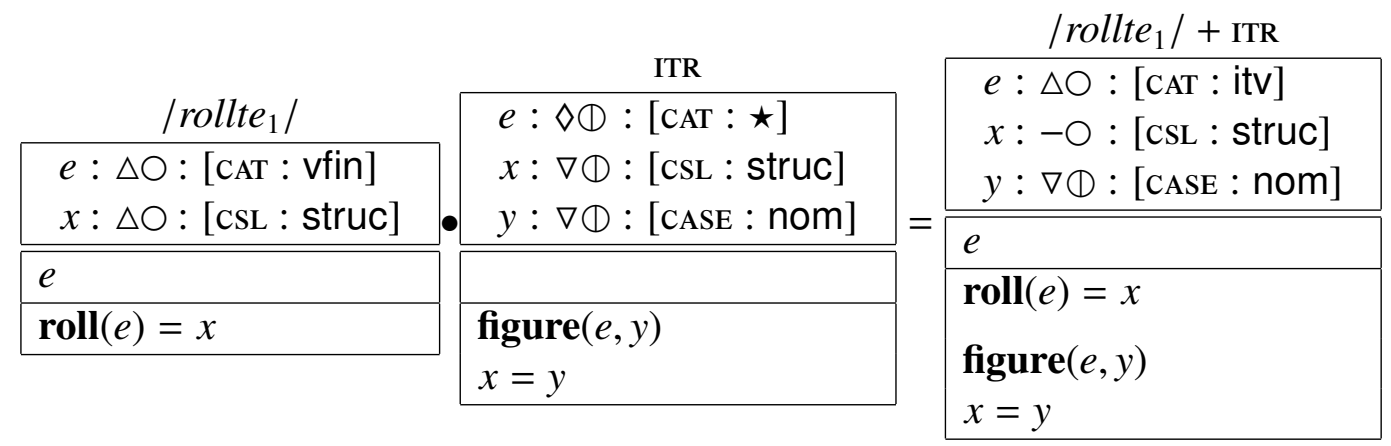

Figure 11: Combining rollte ${ }_{1}$ with ITR.

subject the specific role of entity rolling as well as the construal of figure in the described event (figure 12). Combining/rollte 2 with ITR construction

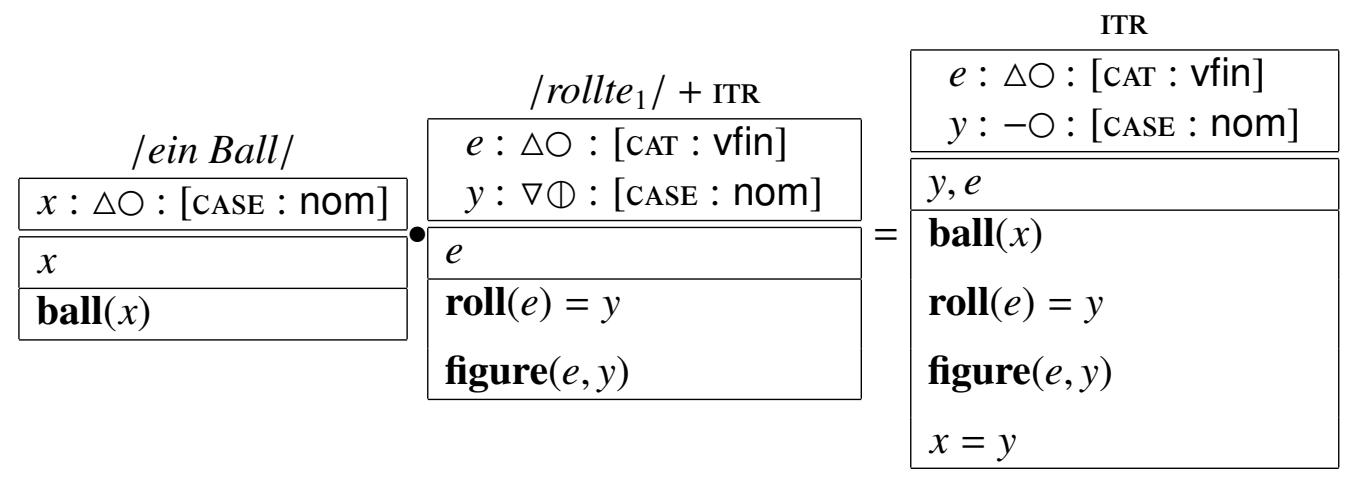

Figure 12: Combining ein Ball with rollte $_{1}+\mathrm{ITR}$ 
identifies the entity whose wheels are rotating with the entity being assigned the nominative case (figure 13). Combining ein Auto with rollte ${ }_{2}+$ ITR (fig-

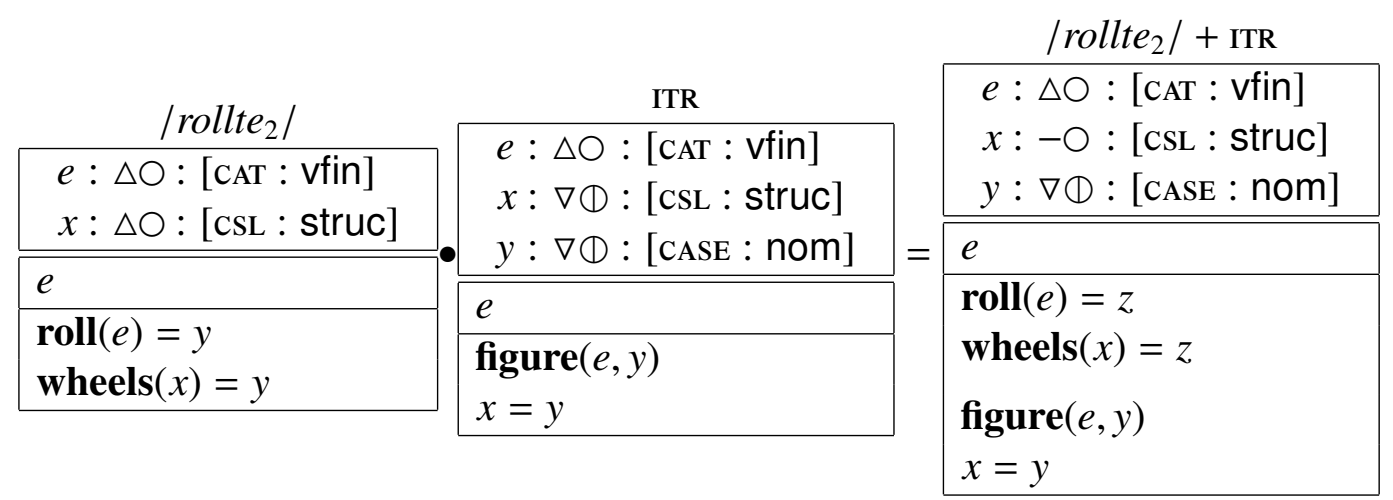

Figure 13: Combining/rollte $2 /$ with ITR

ure 14) identifies the car with the entity construed as the figure of the event, but does not identify it further with the entity rotating along its own axis. This specific semantic role is assigned to the wheels of the car.

\begin{tabular}{|c|c|c|c|}
\hline \multirow[b]{4}{*}{ /ein Auto/ } & & $\mid$ ein Auto $/+\mid$ rollte $_{2} \mid+\mathrm{ACT}$ \\
\hline & $\mid$ rollte $_{2} \mid+$ ITR & & \multirow{2}{*}{$\begin{array}{l}e: \triangle \bigcirc:[\text { CAT }: \text { vfin }] \\
y:-\bigcirc:[\text { CASE }: \text { nom }]\end{array}$} \\
\hline & \multirow{2}{*}{$\begin{array}{l}e: \triangle \bigcirc:[\text { CAT }: \text { vfin }] \\
y: \nabla \emptyset:[\text { CASE }: \text { nom }]\end{array}$} & & \\
\hline & & \multirow{6}{*}{$=$} & $x, e$ \\
\hline$x: \triangle O:[$ CASE $:$ nom] & $e^{\circ}$ & & $\operatorname{car}(x)$ \\
\hline$x$ & \multirow{4}{*}{$\begin{array}{l}\operatorname{roll}(e)=z \\
\text { wheels }(y)=z \\
\text { figure }(e, y)\end{array}$} & & $\operatorname{roll}(e)=z$ \\
\hline \multirow[t]{3}{*}{$\operatorname{car}(x)$} & & & wheels $(y)=z$ \\
\hline & & & figure $(e, y)$ \\
\hline & & & $x=y$ \\
\hline
\end{tabular}

Figure 14: Combining ein Auto with rollte 2 + ITR

The assignment of the role of entity rolling (along its own axis) thus depends on the choice of lexical entry for rollte, and this depends in turn on our knowledge about balls and cars. To make this dependence on extragrammatical knowledge explicit, we describe below an alternative analysis where rollte is monosemous, and the intransitive construction is underspecified in the sense that it introduces an entity $y$ construed as figure and case-marked as nominative without specifying that this entity is to be identified with the entity $x$ construed as prominent or structural (see figure 15). The combination 


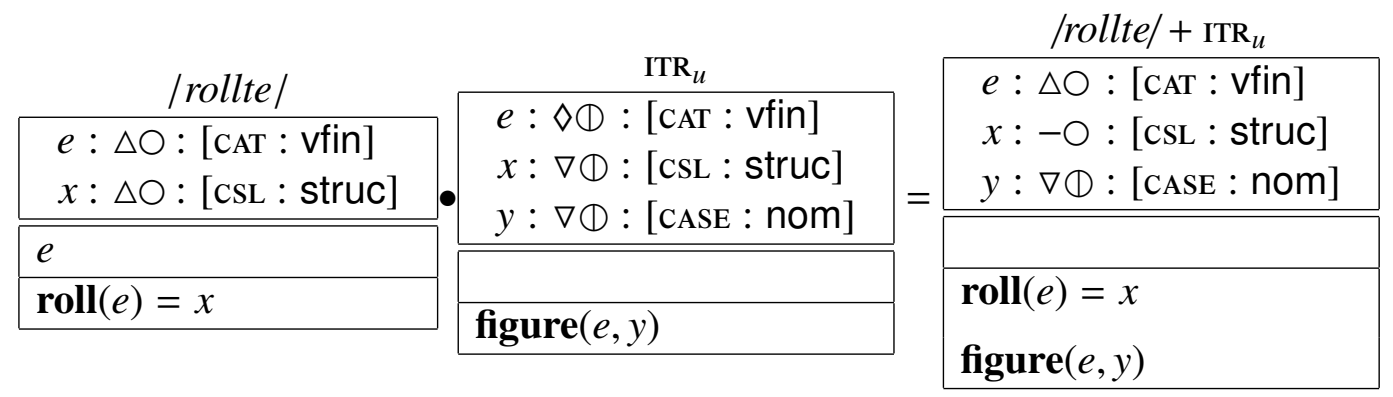

Figure 15: Combining monosemous rollte with underspecified $\operatorname{ITR}_{u}$.

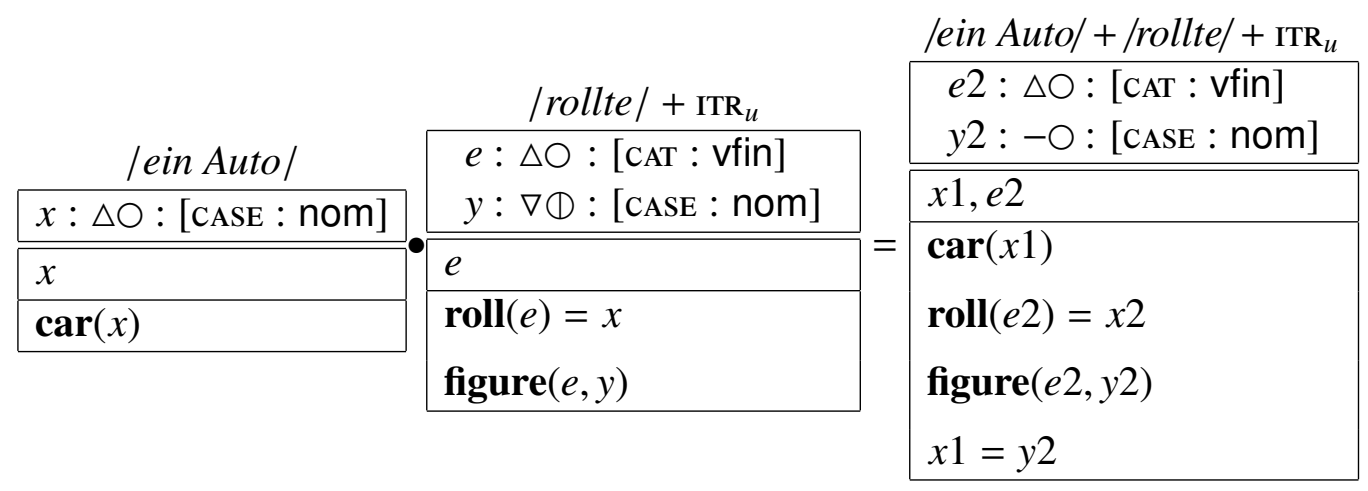

Figure 16: Combining/ein Auto/ with/rollte/ $+\mathrm{ITR}_{u}$.

of /ein Auto/ with /rollte/ $+\mathrm{ITR}_{u}$ is displayed in figure 16. The combination of /ein Ball/ with /rollte/ $+\mathrm{ITR}_{u}$ is displayed in figure 17 . In this analysis the sub-

\begin{tabular}{|c|c|c|c|}
\hline & |rollte| + $\operatorname{ITR}_{u}$ & & /ein Ball/ +/rollte/ + $\mathrm{ITR}_{u}$ \\
\hline /ein Ball/ & \multirow{2}{*}{$\begin{array}{l}e: \triangle \bigcirc:[\text { CAT }: \text { vfin] } \\
y: \nabla \emptyset:[\text { CASE }: \text { nom }]\end{array}$} & \multirow{5}{*}{$=$} & $y:-\mathrm{O}:[$ CASE $:$ nom $]$ \\
\hline$y: \triangle O:[$ CASE $:$ nom] & & & $v e$ \\
\hline $\begin{array}{ll}y \\
y\end{array}$ & $e$ & & ball $(y)$ \\
\hline ball $(y)$ & $\operatorname{roll}(e)=x$ & & J) \\
\hline & figure $(e, y)$ & & $\operatorname{figure}(e, y)$ \\
\hline
\end{tabular}

Figure 17: The combination of /ein Ball/ with/rollte/ $+\mathrm{ITR}_{u}$.

ject is claimed to be the figure of the event, but is not identified with the entity rolling by the grammar. In the next section we propose that the assignment 
of the role of entity rolling is the result of abductive inference to the best explanation involving encyclopedic knowledge as well as default construal rules for rolling balls and cars.

Let us now turn to the grammatical analysis of the examples in (10). First we introduce the lexical entry assumed for schlagen and then the resultative construction involved in these examples. Consider first the sentences (12):
a. Der Hammer schlug auf den Tisch.
the hammer beat/hit on the table
'The hammer hit the table.'
b. Hans schlug (mit dem Hammer) auf den Tisch. Hans beat/hit with the hammer on the table 'Hans hit the table (with the hammer)'

We remain agnostic as to whether the sense of schlug in (12-b) derives from the sense of schlug in (12-a) by means of a causativization operation, or whether schlug in (12) is simply ambiguous. Either way, we propose the entry in figure 18 for schlug. In particular, this sense of schlagen (whether

$$
\begin{array}{|l|}
\multicolumn{1}{c|}{/ \text { schlug/ }} \\
\hline e: \Delta \bigcirc:[\mathrm{CAT}: \text { vfin] } \\
v: \Delta \Phi:[\mathrm{CSL}: \text { obl] } \\
u: \Delta \Phi:[\mathrm{cSL}: \text { prom] } \\
\hline \hline e \\
\hline \operatorname{hit}_{1}(e)=u \\
\operatorname{hit}_{2}(e)=v \\
\operatorname{hit}_{3}(e)=w \\
\hline
\end{array}
$$

Figure 18: Lexical entry for schlug.

derived or not) involves three participants, namely an entity hitting (hit $\mathbf{H}_{1}$ ), and an entity moving (hit ${ }_{2}$ ) and eventually hitting another entity (hit $\left.{ }_{3}\right)$. The entity hitting (as opposed to the entity moving) is construed as the prominent (or designated) argument, and the entity hit is construed as an oblique argument. The entity moving towards the target is not part of the construal imposed on this lexical item. This difference in construal between the moved and the target entities explains why the moving entity can be realized as an adjunct (13-b) in a resultative construction, ${ }^{12}$ whereas the targeted entity cannot be so realized (13-c).

\footnotetext{
${ }^{12}$ See Goldberg \& Jackendoff (2004) for an overview of the English resultative construction, who refer to the construction instantiated by (13-a) as the 'causative path resultative'. For a comparison between English and German resultatives see e.g. Boas (2003).
} 

a. Hans schlug ein Loch in die Wand.
Hans hit a hole in the wall
b. Hans schlug mit dem Hammer ein Loch in die Wand.
Hans hit with the hammer a hole in the wall
c. *Hans schlug auf den Tisch ein Loch in die Wand.
Hans hit on the table a hole in the table

The resultative construction (i) combines with a verb denoting an event $e$ (represented as $e: \nabla \oplus:[\mathrm{CAT}: \star]^{13}$ in the referent system for the resultative construction), (ii) requires that one argument of the verb be construed as prominent (i.e. $x: \diamond \Phi:$ [CASE : prom]), (iii) absorbs any other arguments of the verb with higher level construal ${ }^{14}$ (i.e. $y: \nabla \Phi:$ [CASE : obl]), (iv) introduces a new event $f$ (i.e. $f: \Delta \mathrm{O}:$ [CAT : $\star$ ]) consisting of $e$ and the state $s$ resulting from $e$ (i.e. $e \sqsubseteq f \wedge s \sqsubseteq f$ ), (v) specifies that the figure of the state resulting from $e$ is to be construed as a structural argument (i.e. figure $(s, z)$ ), and (vi) requires a prepositional phrase governing the accusative $\left(s: \nabla \Phi:\left[\mathrm{CAT}: \mathrm{pp}_{a c c}\right]\right){ }^{15}$ Crucially, the resultative construction does not assign a specific semantic role of the verb to the direct object denotation. ${ }^{16}$

The semantic composition of the lexical entry for schlug with the resultative construction, illustrated in figure 19, proceeds by identifying the variables $e, v, u$ of schlug with the variables $e, y, x$ of the resultative construction, respectively. Next this structure combines with the transitive con-

\footnotetext{
${ }^{13}$ The star $\star$ stands for the set of all values defined for an attribute.

${ }^{14}$ Since the moving entity has no construal at the higher level, it does not get absorbed by the resultative construction, explaining the contrast between (13-b) and (13-c).

${ }^{15}$ The contrast in (15) can be explained if the resultative construction does not add a designed argument to the event, but checks whether it already has one.
}
a. Der Hammer fiel auf den Boden. the hammer fell on the:ACC ground 'The hammer fell on the ground'.
b. Der Hammer schlug auf den Boden. the hammer hit on the:ACC ground 'The hammer hit against the ground.'
a. *Hansfiel den Hammer auf den Boden Hans fell the:ACC Hammer on the:ACC ground Int.: 'Hans caused the Hammer to fall on the ground'.
b. Hans schlug den Hammer auf den Boden. Hans hit the:ACC hammer on the:ACC ground 'Hans hit the hammer against the ground.'

\footnotetext{
${ }^{16}$ Since the hole in (13-a) does not literally move along a path, we have refrained from specifying as part of the resultative construction that the direct object denotation moves along a path. Alternatively, one could assume that in (13-a) the hole moves figuratively. This choice does not affect the point that the construction does not assign a specific semantic role to the direct object denotation.
} 


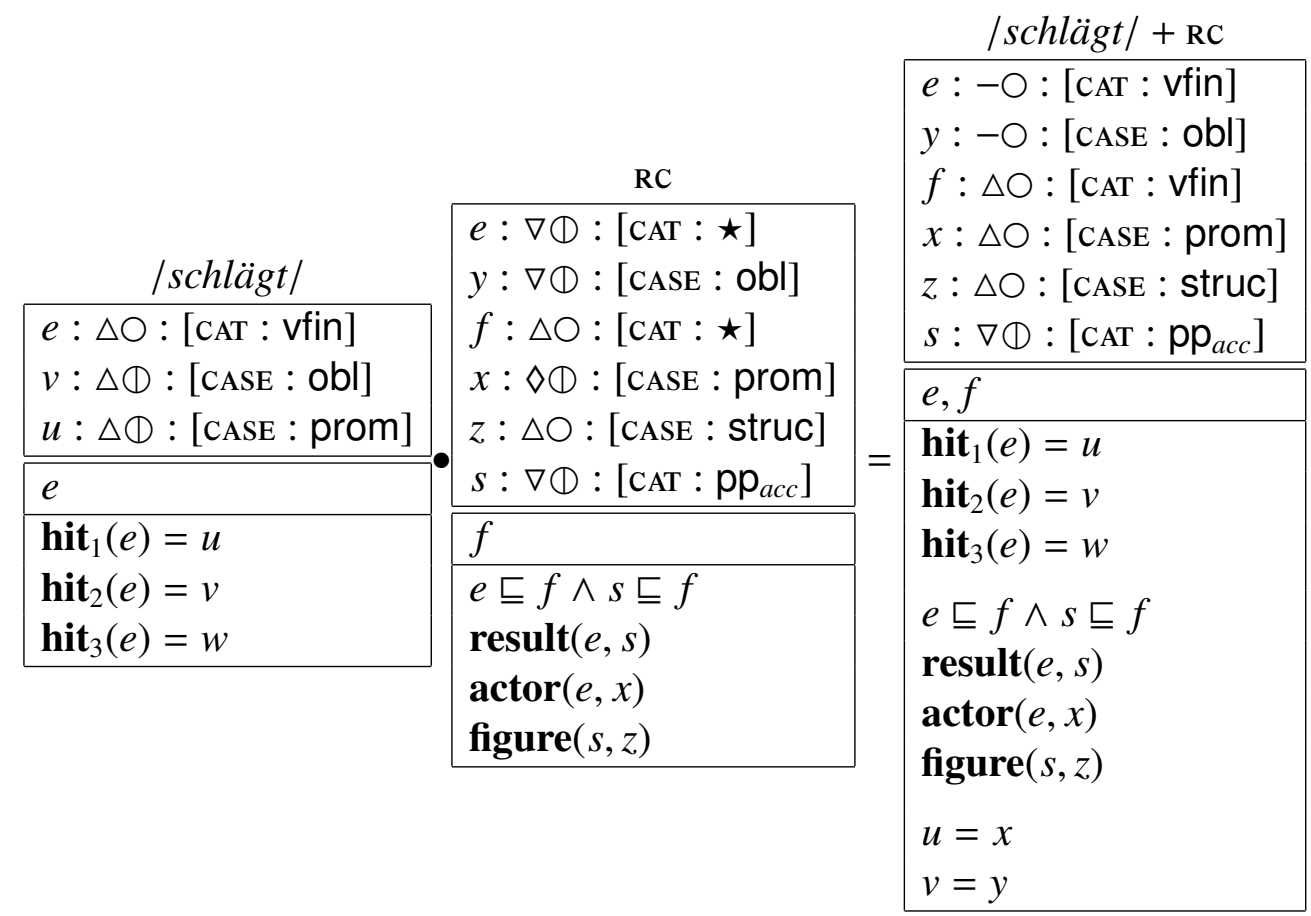

Figure 19: Composing schlug with the resultative construction.

struction (illustrated in figure 20), which (i) checks that the verb is finite ( $f: \diamond \Phi:$ [CAT : vfin]), (ii) trades in the construal of the designated argument $\left(x: \nabla \oplus:\left[\mathrm{CSL}:\right.\right.$ prom]) for the nominative case $\left(x^{\prime}: \nabla \oplus:\right.$ [CASE $:$ nom] and $\left.x=x^{\prime}\right)$, (iii) trades in the construal of the structural argument $(z: \nabla \oplus$ : [CSL : struc]) for the accusative case $\left(z^{\prime}: \nabla \Phi:\right.$ [CASE : acc] and $\left.z=z^{\prime}\right)$, and (iv) specifies that the arguments $x^{\prime}$ and $z^{\prime}$ are instigator and theme of the event $f$, respectively. Combining this with einen Hammer is illustrated in figure 21 . And finally, the combination of the accusative governing PP in die Wand with the verb phrase is displayed in figure 22. Assuming that every sentence imposes exactly one construal on each event/state expressed in it, there can only be one figure for the state $s$, and therefore $u$ and $z$ refer to the same entity, namely the hammer. 


\begin{tabular}{|c|c|c|c|}
\hline \multirow[b]{4}{*}{ |schlägt| + RC } & \multirow[b]{5}{*}{ TR } & & |schlägt| + RC + TR \\
\hline & & \multirow{6}{*}{\multicolumn{2}{|c|}{$\begin{array}{l}f: \triangle \bigcirc:[\mathrm{cAT}: \text { vfin] } \\
x:-\bigcirc:[\mathrm{cSL}: \text { prom] } \\
z:-\bigcirc:[\mathrm{cSL}: \text { struc] } \\
x^{\prime}: \nabla \oplus:[\mathrm{cASE}: \text { nom] }] \\
z^{\prime}: \nabla \Phi:[\mathrm{cASE}: \mathrm{acc}] \\
s: \nabla \emptyset:\left[\mathrm{cAT}: \mathrm{pp}_{a c c}\right] \\
\end{array}$}} \\
\hline & & & \\
\hline & & & \\
\hline$f: \Delta O:[$ CAT $:$ vfin] & & & \\
\hline$x: \triangle O:[\mathrm{CsL}:$ prom $]$ & \multirow{5}{*}{$\begin{array}{l}f: \diamond \Phi:[\mathrm{CAT}: \text { vfin] } \\
x: \nabla \Phi:[\mathrm{CSL}: \text { prom] } \\
z: \nabla \Phi:[\mathrm{cSL}: \text { struc] } \\
x^{\prime}: \nabla \Phi:[\text { cASE }: \text { nom] }] \\
z^{\prime}: \nabla \Phi:[\text { cASE }: \text { acc }]\end{array}$} & & \\
\hline$z: \Delta O:[\operatorname{csL}:$ struc $]$ & & & \\
\hline$s: \nabla \oplus:\left[\mathrm{cAT}: \mathrm{pp}_{a c c}\right]$ & & \multirow[b]{3}{*}{$=$} & e \\
\hline$e, f$ & & & $\operatorname{hit}_{1}(e)=x$ \\
\hline $\operatorname{hit}_{1}(e)=x$ & & & $\operatorname{hit}_{2}(e)=v$ \\
\hline $\operatorname{hit}_{2}(e)=v$ & $f$ & & $\operatorname{hit}_{3}(e)=w$ \\
\hline $\operatorname{hit}_{3}(e)=w$ & instigator $\left(f, x^{\prime}\right)$ & & $e \sqsubseteq f \wedge s \sqsubseteq f$ \\
\hline$e \sqsubseteq f \wedge s \sqsubseteq f$ & theme $\left(f, z^{\prime}\right)$ & & $\operatorname{result}(e, s)$ \\
\hline $\operatorname{result}(e, s)$ & $x=x^{\prime}$ & & $\operatorname{actor}(e, x)$ \\
\hline $\operatorname{actor}(e, x)$ & $z=z^{\prime}$ & & figure $(s, z)$ \\
\hline figure $(s, z)$ & & & $\operatorname{instigator}\left(f, x^{\prime}\right)$ \\
\hline & & & $\begin{array}{l}\text { theme }\left(f, z^{\prime}\right) \\
x=x^{\prime} \\
z=z^{\prime}\end{array}$ \\
\hline
\end{tabular}

Figure 20: Combining schlug+RC with the intransitive construction. 


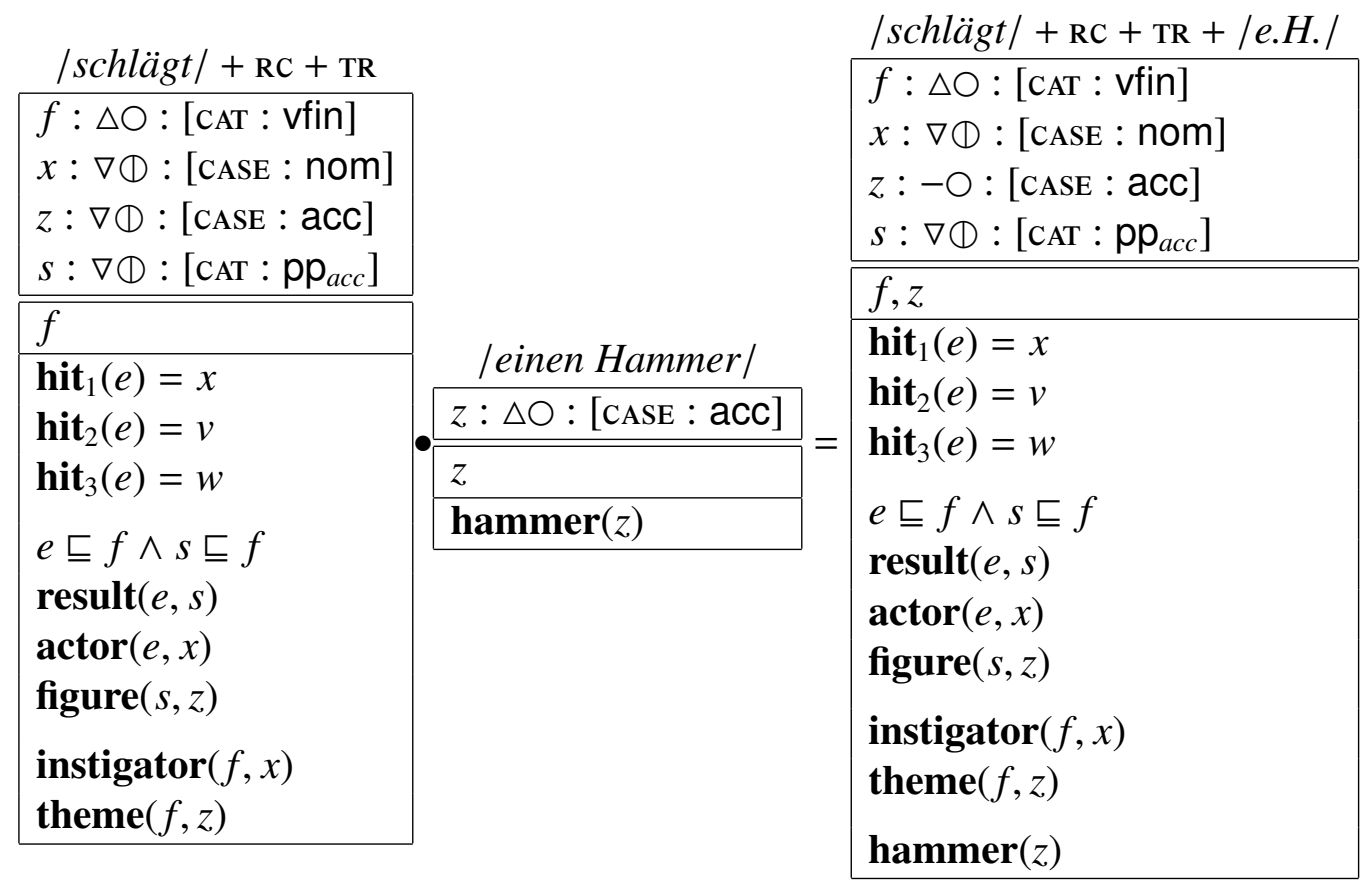

Figure 21: Combining the direct object einen Hammer.

\section{Contextual enrichment via abduction}

The arguments that are not assigned a specific semantic role by grammatical means may be assigned one by extragrammatical means as argued in section 2. This contextually enriched argument assignment of specific semantic roles is formalized by means of abductive inference, which proceeds as follows. If (i) we observe (or know) $\psi$ and (ii) we know that $\psi$ can be explained on the assumption that $\phi$ (analyzed by saying that $\phi \rightarrow \psi$ belongs to the knowledge base), then we assume that $\phi .{ }^{17}$

To illustrate the role of abduction in the interpretation of sentence (2), consider the following default construal rules, saying that (by default) rolling balls as well as cars moving on rolling wheels are construed as figures in the respective events: ${ }^{18}$

$$
\begin{array}{ll}
\text { a. } & \phi_{1}:=\operatorname{ball}(x) \wedge \operatorname{roll}(e)=x \rightarrow \operatorname{figure}(e, x) \\
\text { b. } & \phi_{2}:=\operatorname{car}(x) \wedge \operatorname{wheels}(x)=y \wedge \operatorname{roll}(e)=y \rightarrow \operatorname{figure}(e, x)
\end{array}
$$

\footnotetext{
${ }^{17}$ See Hobbs (2008) and references therein for a survey of (the use of) abduction in natural language understanding.

${ }^{18}$ Free variables in the formulas representing world knowledge should be understood as being universally quantified over.
} 


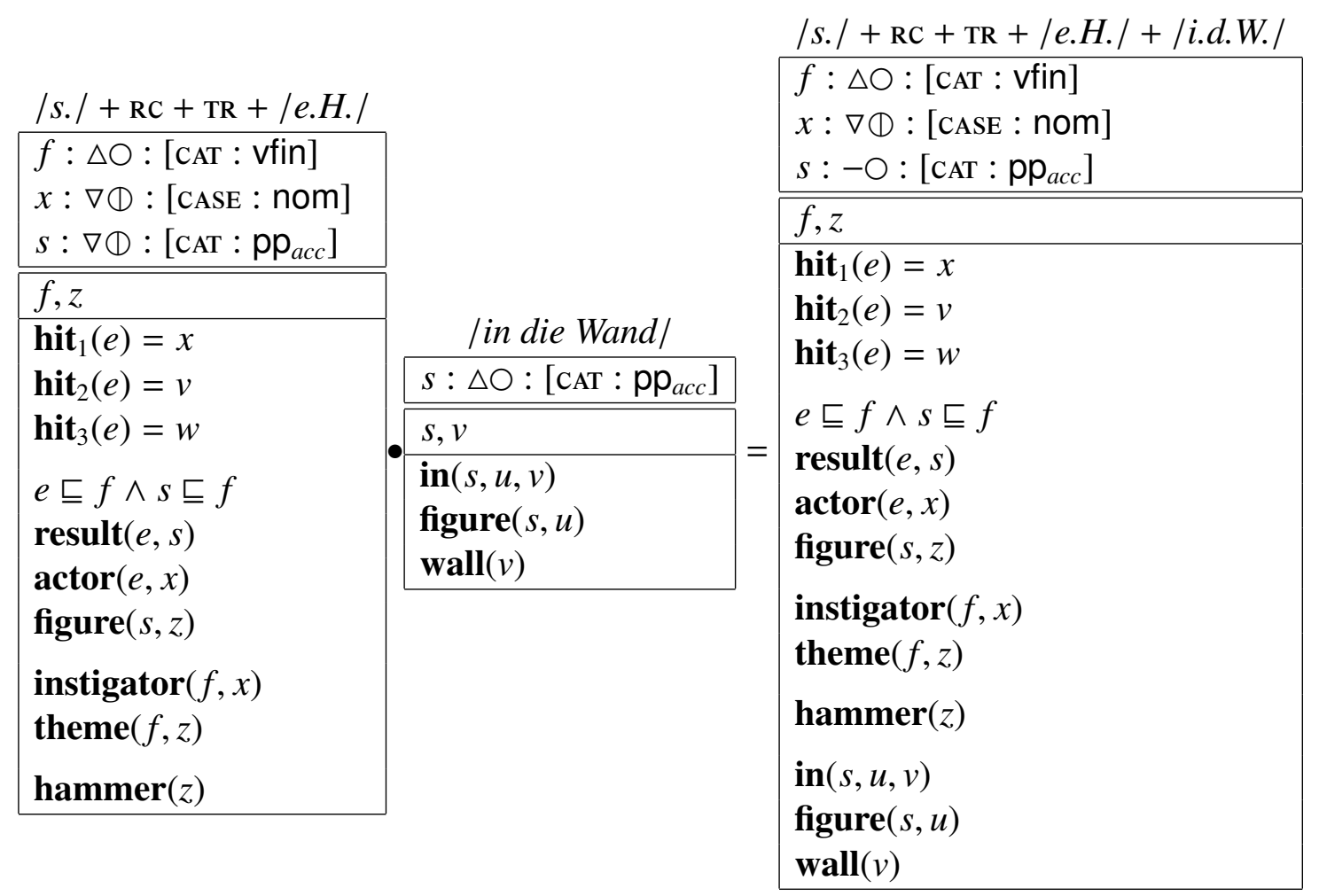

Figure 22: Combining the PP in die Wand. 
If the DRS for ein Ball rollte (see below) contains the information that the ball $y$ is the figure in rolling event $e$, and if we know $\phi_{1}$, then we can plausibly (and defeasibly) explain the fact that $y$ is the figure in $e$ if we assume that the ball $y$ is rotating along its own axis. This assumption, represented as $\operatorname{roll}(e)=y$, is therefore added to the DRS by an inference step of abductive $\phi_{1}$-enrichment, illustrated in figure 23 . And since the entity rolling in a rolling

$$
\begin{array}{|l|l|l|}
\hline y, e & y, e \\
\hline \operatorname{roll}(e)=x \\
\operatorname{figure}(e, y) \\
\operatorname{ball}(y)
\end{array} \sim_{\phi_{1}} \begin{array}{l|}
\operatorname{roll}(e)=x \\
\operatorname{figure}(e, y) \\
\operatorname{ball}(y) \\
\operatorname{roll}(e)=y \\
\hline
\end{array}
$$

Figure 23:

event is uniquely determined, it follows that the entity $x$ participating as the rolling entity in the event is identical with the ball $y$. The necessary notion of abductive $\phi$-enrichment of a DRS is defined as follows:

Definition 4.1 Let $\phi:=(\forall \sigma)(\psi \rightarrow \chi)$ be in the knowledge base, and let $\Delta=\langle U, C\rangle$ be a DRS. If $\chi \in C$ then the abductive $\phi$-enrichment of $\Delta$ results in $\Delta^{\prime}=\left\langle U, C^{\prime}\right\rangle$, where $C^{\prime}$ results from adding $\psi$ to $C$ (as an assumption). For abductive $\phi$-enrichment of $\Delta$ into $\Delta^{\prime}$ we write $\Delta \sim_{\phi} \Delta^{\prime}$.

By abductive $\phi_{2}$-enrichment of ein Auto rollte we can add to the DRS that the wheels $z$ of the car $y$ are rolling (figure 24), and given the uniqueness of event participants it follows that the entity $x$ participating as the rolling entity in the rolling event is identical with the wheels $z$ of the car $y$.

To analyze the enrichment of (3) we assume knowledge of $\phi_{3}$, i.e. that a car rolling along its own axis may end up with its wheels up.

$$
\phi_{3}:=\operatorname{car}(x) \wedge \operatorname{roll}(e)=x \wedge \operatorname{etc}(e) \rightarrow \operatorname{wheels.up}(x)
$$

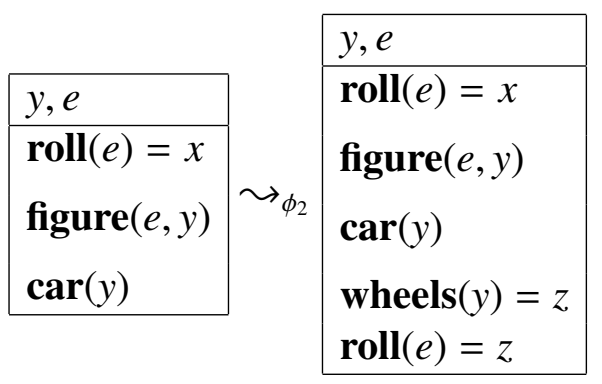

Figure 24: Contextual enrichment of ein Auto rollte. 


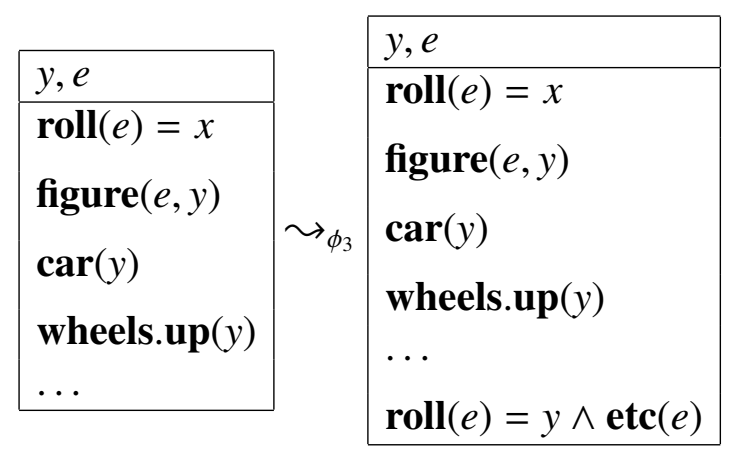

Figure 25: Enrichment of (3)

The abductive $\phi_{3}$-enrichment of the DRS of (3) results in the assignment of the specific role of entity rolling to the car itself, illustrated in figure 25. While in the case of rollen it is possible to claim that it is only the choice of lexical item that is dependent on extragrammatical resources, and that once the choice has been made the assignment of specific semantic roles to clause arguments is determined, this cannot convincingly be maintained for the examples in (9) and (10), as discussed in section 2.

To enrich the phrase einen Hammer in die Wand schlagen by abductive inference, assume that if a hammer is hit against a wall and further conditions hold, then the hammer ends up in the wall.

$$
\begin{aligned}
& \phi_{4}:=\operatorname{hit}_{2}(e)=m \wedge \operatorname{hit}_{3}(e)=n \wedge \operatorname{etc}(e) \rightarrow(\exists s)(\operatorname{result}(e, s) \wedge \\
& \operatorname{in}(s, m, n))^{19}
\end{aligned}
$$

Since a hammer has ended up in the wall a plausible explanation is that it was hit against the wall. So by abductive $\phi$-enrichment, we add the assumption that the entity moving in the hitting event is the hammer $m$ and the entity hit is the wall $n$, as illustrated in figure 26 .

If something is hit against a nail held against a wall and further conditions hold, then the nail ends up in the wall.

$$
\begin{aligned}
& \phi_{5}:=\operatorname{nail}(m) \wedge \operatorname{wall}(n) \wedge \operatorname{held} \_\operatorname{against}(m, n) \wedge \operatorname{hit}_{3}(e)=m \wedge \operatorname{etc}(e) \rightarrow \\
& \operatorname{result}(e, s) \wedge \operatorname{in}(s, m, n)
\end{aligned}
$$

Since a nail has ended up in the wall a plausible explanation is that the nail was hit by something as it was held against the wall. So by abductive $\phi_{5^{-}}$ enrichment, we add the assumption that the target in the hitting event is the nail, as illustrated in figure 27.

Summing up, the referent introduced by the direct object is identified with some participant in the state of affairs denoted by the verb not via grammatical information encoded in referent systems, but via abductive reasoning with

\footnotetext{
${ }^{19} \operatorname{in}(s, m, n)$ is to be understood as: $s$ is the state of $m$ being in $n$.
} 


\begin{tabular}{|c|c|c|}
\hline & & $|s . /+\mathrm{RC}+\mathrm{TR}+|$ e.H..$/+\mid$ i.d.W. $\mid$ \\
\hline $\mid$ s. $/+\mathrm{RC}+\mathrm{TR}+\mid$ e.H. $/+\mid$ i.d.W. $/$ & & $f, z, s$ \\
\hline$f, z, s$ & & $\operatorname{hit}_{1}(e)=x$ \\
\hline $\operatorname{hit}_{1}(e)=x$ & & $\operatorname{hit}_{2}(e)=v$ \\
\hline $\operatorname{hit}_{2}(e)=v$ & & $\operatorname{hit}_{3}(e)=w$ \\
\hline $\operatorname{hit}_{3}(e)=w$ & & $e \sqsubseteq f \wedge s \sqsubseteq f$ \\
\hline$e \sqsubseteq f \wedge s \sqsubseteq f$ & & $\operatorname{result}(e, s)$ \\
\hline $\operatorname{result}(e, s)$ & & $\operatorname{actor}(e, x)$ \\
\hline $\operatorname{actor}(e, x)$ & $\sim$ & figure $(s, z)$ \\
\hline figure $(s, z)$ & $\phi_{4}$ & $\operatorname{instigator}(f, x)$ \\
\hline $\operatorname{instigator}(f, x)$ & & theme $(f, z)$ \\
\hline theme $(f, z)$ & & $\operatorname{hammer}(z)$ \\
\hline $\operatorname{hammer}(z)$ & & $\operatorname{in}(s, m, n)$ \\
\hline $\operatorname{in}(s, m, n)$ & & figure $(s, m)$ \\
\hline figure $(s, m)$ & & $\operatorname{wall}(n)$ \\
\hline wall $(n)$ & & $\operatorname{hit}_{2}(e)=m$ \\
\hline & & $\operatorname{hit}_{3}(e)=n$ \\
\hline
\end{tabular}

Figure 26: Contextual enrichment of einen Hammer in die Wand schlagen. 


\begin{tabular}{|c|c|c|}
\hline \multirow[b]{2}{*}{$\mid$ s. $/+\mathrm{RC}+\mathrm{TR}+\mid$ e.N..$/+$ |i.d.W. $/$} & & /s./ + $\mathrm{RC}+\mathrm{TR}+\mid$ e.N..$/+\mid$ i.d.W. $/$ \\
\hline & & $f, z, s$ \\
\hline$f, z, s$ & & $\operatorname{hit}_{1}(e)=x$ \\
\hline $\operatorname{hit}_{1}(e)=x$ & & $\operatorname{hit}_{2}(e)=v$ \\
\hline $\operatorname{hit}_{2}(e)=v$ & & $\operatorname{hit}_{3}(e)=w$ \\
\hline $\operatorname{hit}_{3}(e)=w$ & & $e \sqsubseteq f \wedge s \sqsubseteq f$ \\
\hline$e \sqsubseteq f \wedge s \sqsubseteq f$ & & $\operatorname{result}(e, s)$ \\
\hline $\operatorname{result}(e, s)$ & & $\operatorname{actor}(e, x)$ \\
\hline $\operatorname{actor}(e, x)$ & $\sim$ & figure $(s, z)$ \\
\hline figure $(s, z)$ & $\varphi_{5}$ & $\operatorname{instigator}(f, x)$ \\
\hline instigator $(f, x)$ & & theme $(f, z)$ \\
\hline theme $(f, z)$ & & $\operatorname{nail}(z)$ \\
\hline $\operatorname{nail}(z)$ & & $\operatorname{in}(s, m, n)$ \\
\hline $\operatorname{in}(s, m, n)$ & & figure $(s, m)$ \\
\hline figure $(s, m)$ & & $\mathbf{w a l l}(n)$ \\
\hline wall $(n)$ & & $\operatorname{hit}_{3}(e)=n$ \\
\hline & & held.against $(m, n)$ \\
\hline
\end{tabular}

Figure 27: Contextual enrichment of einen Nagel in die Wand schlagen.

encyclopedic knowledge.

\section{Conclusion}

The paper proposed a formally explicit analysis of the interaction of grammar and world knowledge in the linking of clause arguments to specific semantic roles. The proposal hinges on the hypothesis that semantic composition consists in the identification of the referents introduced by NPs with the participants involved in the states of affairs described by predicates, with both referents and participants being represented by means of free variables. Referent systems associate with each free variable occurring in the semantic representation the morphosyntactic information relevant for its identification, and thus capture the grammar's contribution to argument linking. The contribution of extragrammatical resources to the identification of free variables is modeled in terms of enrichment of DRSs by means of abductive reasoning based on encyclopedic knowledge. The interaction between grammar and encyclopedic knowledge in the assignment of specific semantic roles to clause arguments is illustrated by an analysis of the (causative path) resultative construction. 


\section{References}

Boas, Hans C. 2003. A constructional approach to resultatives Stanford monographs in linguistics. CSLI Publications.

Cappelen, Herman \& Ernie Lepore. 2005. Insensitive semantics: A defense of Semantic Minimalism and Speech Act Pluralism. Oxford: Blackwell Publishing.

Dowty, David. 1991. Thematic proto-roles and argument selection. Language $67.547-619$.

Goldberg, Adele E. 1995. Constructions: A construction grammar approach to argument structure. Chicago: University of Chicago Press.

Goldberg, Adele E. 2006. Constructions at Work: The Nature of Generalization in Language. Oxford: Oxford University Press.

Goldberg, Adele E. \& Ray Jackendoff. 2004. The english resultative as a family of constructions. Language 80. 532-568.

Haider, Hubert. 1986. Fehlende Argumente: vom Passiv zu kohärenten Infinitiven. Linguistische Berichte 101. 3-33.

Hobbs, Jerry R. 2008. Abduction in natural language understanding. In Laurence Horn \& Gregory Ward (eds.), The handbook of pragmatics, 724-741. Blackwell Publishing Ltd.

Kamp, Hans \& Uwe Reyle. 1993. From discourse to logic. Dordrecht: Kluwer.

Klein, Udo. 2012. Quantification, witness sets and conservativity. In Proceedings of the 29th west coast conference on formal linguistics, University of Arizona. To appear.

Kracht, Marcus. 1999. Agreement Morphology, Argument Structure and Syntax. Unpublished manuscript.

Krifka, Manfred. 1998. The Origins of Telicity. In Susan Rothstein (ed.), Events and grammar, 197-235. Dordrecht: Kluwer.

Langacker, Ronald W. 1987. Foundations of cognitive grammar, vol. 1. Stanford, California: Stanford University Press.

Levin, Beth \& Malka Rappaport Hovav. 2005. Argument realisation Research Surveys in Linguistics. Cambridge: Cambridge University Press.

Recanati, François. 2004. Literal meaning. Cambridge University Press. 
Vermeulen, Kees F. M. 1995. Merging without mystery or: Variables in dynamic semantics. Journal of Philosophical Logic 24(4). 405-450.

Vogel, Ralf. 1998. Polyvalent verbs: Humboldt-Universität Berlin dissertation.

Zeevat, Henk. 1989. A compositional approach to discourse representation theory. Linguistics and Philosophy 12.95-131.

\section{A Referent systems}

Definition 1.2 A referent $\mathbf{x}^{-} \sigma$ consists of the variable symbol $x$ followed by a sequence $\sigma \in\{\mathbf{1}, \mathbf{2}\}^{*}$. Let $R$ be the set of such referents.

Convention 1.1 To ease readability we use also the symbols $e, f, g, h, x, y, z, u, v, w, \ldots$ to stand for referents.

Definition 1.3 A renaming $r \subset R^{2}$ is an injective function which suffixes its argument either with a 1 or with a 2. $r$ is a renaming of a referent system $\alpha=\left[\mu_{1}, \ldots, \mu_{n}\right]$ iff the domain $D \subset R$ of $r$ is the set of referents $\left\{\operatorname{ref}\left(\mu_{i}\right): 1 \leq\right.$ $i \leq n\}$.

Definition 1.4 Let $\Delta_{1}=\left\langle U_{1}, C_{1}\right\rangle$, and $\Delta_{2}=\left\langle U_{2}, C_{2}\right\rangle$ be two DRSs, where $\Delta_{1}$ contains the variables $x_{1}, \ldots, x_{m}$ and $\Delta_{2}$ contains the variables $y_{1}, \ldots, y_{n}$. Then $\bullet\left(\Delta_{1}, \Delta_{2},\left\langle r_{1}, r_{2}\right\rangle\right)$ is defined iff $(i)$ the domain of $r_{1}$ is the set of variables in $\Delta_{1}$, and (ii) the domain of $r_{2}$ is the set of variables in $\Delta_{2}$. In this case $\bullet\left(\left\langle U_{1}, C_{1}\right\rangle,\left\langle U_{2}, C_{2}\right\rangle,\left\langle r_{1}, r_{2}\right\rangle\right)=\left\langle r_{1}\left[U_{1}\right] \cup r_{2}\left[U_{2}\right], r_{1}\left[C_{1}\right] \cup r_{2}\left[C_{2}\right]\right\rangle$, where

(i) $r_{1}\left[U_{1}\right]=\left\{r_{1}\left(x_{i}\right): i \leq m\right\}, r_{2}\left[U_{2}\right]=\left\{r_{2}\left(x_{j}\right): j \leq n\right\}$

(ii) $r_{1}\left[C_{1}\right]=\left\{\phi_{i}\left[r_{1}\right]: \phi_{i} \in C_{1}\right\}, r_{2}\left[C_{2}\right]=\left\{\phi_{j}\left[r_{2}\right]: \phi_{j} \in C_{2}\right\}$

(iii) $\phi[r]$ is the result of replacing every variable $x$ in $\phi$ by $r(x)$

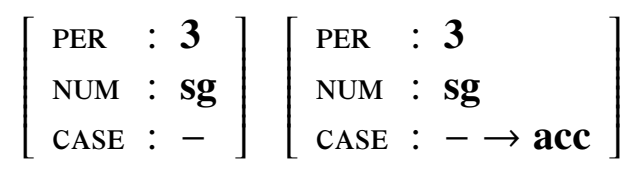

Definition 1.5 A vertical diacritic $v d$ is a subset of $\{\Delta, \nabla\}$. A horizontal diacritic $h d$ is a subset of $\{\otimes, \oslash\}$. 
Convention 1.2 For ease of readability, we use the following conventions for representing vertical and horizontal diacritics:

\begin{tabular}{|c|c|c|c|c|c|}
\hline & definition & convention & & definition & convention \\
\hline$v d$ & $\varnothing$ & - & $h d$ & $\varnothing$ & 0 \\
\hline & $\{\Delta\}$ & $\Delta$ & & $\{\nexists\}$ & $\theta$ \\
\hline & $\{\nabla\}$ & $\nabla$ & & $\{\otimes\}$ & $\theta$ \\
\hline & $\{\Delta, \nabla\}$ & $\diamond$ & & $\{\otimes, \otimes\}$ & (1) \\
\hline
\end{tabular}

Definition 1.6 A diacritic $d$ is a pair $\langle v d, h d\rangle$ consisting of a vertical diacritic $v d$ and a horizontal diacritic $h d$. A diacritic $\langle v d, h d\rangle$ is a legal diacritic iff $(\nabla \in v d \vee \nabla \in v d) \leftrightarrow h d \neq \varnothing$. The diacritic $\langle\varnothing, \varnothing\rangle$ is called trivial.

The categorial information will be represented by so called labels.

Definition 1.7 A label space $\mathbf{N}$ is a triple $\langle A, V, f\rangle$, where $A$ is a finite nonempty set of attributes, $V$ is a finite non-empty set of values disjoint from $A$, and $f: A \rightarrow \wp(V)$ is a valuation function assigning every attribute in $A$ a subset of $V$.

Definition 1.8 A simple label $N$ (over a label space $\mathbf{N}=\langle A, V, f\rangle$ ) is a feature structure over $\mathbf{N}$. A transformer label $\mathfrak{R}$ is a pair $\langle N, N\rangle$ of simple labels.

We shall use the more compact notation:

$$
\left[\begin{array}{lll}
\mathrm{CAT} & : & \mathbf{v} \\
\mathrm{PRE} & : & - \\
\mathrm{SUFF} & : & -\rightarrow+
\end{array}\right] \text { for }\left\langle\left[\begin{array}{lll}
\mathrm{CAT} & : & \mathbf{v} \\
\mathrm{PRE} & : & - \\
\mathrm{SUFF} & : & -
\end{array}\right],\left[\begin{array}{lll}
\mathrm{CAT} & : & \mathbf{v} \\
\mathrm{PRE} & : & - \\
\mathrm{SUFF} & : & +
\end{array}\right]\right\rangle
$$

Let $n . a$ be the value of the simple label $n$ for the feature $a$. The unification $n_{1} \sqcap n_{2}$ is defined if for all attributes $a \in A$ it holds that $n_{1} . a \cap n_{2} . a \neq \emptyset$. Then $n_{1} \sqcap n_{2}=\left\{\left[a: v_{1} \cap v_{2}\right]:\left[a: v_{1}\right] \in n_{1} \wedge\left[a: v_{2}\right] \in n_{2}\right\}$.

We can now put together the information relevant for the identification of a referent, by defining so-called argument identification statements:

Definition 1.9 A triple $\alpha=\langle x,\langle v d, h d\rangle, n\rangle$ is an argument identification statement (AIS) iff (i) $x$ is a referent, $\langle v d, h d\rangle$ a legal diacritic with $|v d|<2$, and $n$ a simple label (over a label space $N$ ), or (ii) $x$ is a referent, $\langle v d, h d\rangle$ a legal diacritic with $v d=\{\Delta, \nabla\}$, and $n$ a transformer label. Further, let $\operatorname{ref}(\alpha)=x, \operatorname{vd}(\alpha)=v d, \mathbf{h d}(\alpha)=h d, \mathbf{n}(\alpha)=n$.

Definition 1.10 A list of argument identification statements $\left[\mu_{1}, \ldots, \mu_{m}\right], m \geq$ 1 , is called a referent system.

Definition 1.11 The leftward merge of two AISs $\mu \triangleleft v$ is defined iff $(i) \otimes \in$ $\mathbf{h d}(v)$, (ii) $\Delta \in \mathbf{v d}(\mu)$, (iii) $\nabla \in \mathbf{v d}(v)$, and (iv) $\mathbf{n}(\mu) \cdot \mathbf{n}(v)$ is defined. If defined, then:

$$
\mu \triangleleft v=\left\langle\operatorname{ref}(\mu)^{-} 1,\langle\operatorname{vd}(\mu) \cap \mathbf{v d}(v), \mathbf{h d}(\mu)\rangle, \mathbf{n}(\mu) \cdot \mathbf{n}(v)\right\rangle
$$


where the resulting label $m \cdot n$ is:

$\mathbf{n}(\mu) \cdot \mathbf{n}(v)= \begin{cases}\mathbf{n}(\mu) \sqcap \mathbf{n}(v), & \text { if } \mathbf{n}(\mu), \mathbf{n}(v) \text { are unifiable simple labels } \\ B, & \text { if } \mathbf{n}(\mu)=\langle A, B\rangle, \mathbf{n}(v)=C, \text { and } A \text { unifies with } C \\ C, & \text { if } \mathbf{n}(\mu)=A, \mathbf{n}(v)=\langle C, D\rangle, \text { and } A \text { unifies with } D \\ \text { undefined, } & \text { otherwise }\end{cases}$

The leftward merge of referent systems is defined as follows:

Definition 1.12 Let $\alpha=\left[\mu_{1}, \ldots, \mu_{m}\right]$ and $\beta=\left[v_{1}, \ldots, v_{n}\right]$ be two referent systems. The leftward merge $\bullet\left(\alpha, \beta,\left\langle r_{1}, r_{2}\right\rangle\right)$ of $\alpha$ and $\beta$ relative to the renaming $\left\langle r_{1}, r_{2}\right\rangle$ is defined iff

- $\alpha$ is saturated

- there is an $i, 1 \leq i \leq n$ such that $\mu_{1}$ accesses $v_{i}$

- for every $k$ with $1 \leq k \leq m$

$$
\begin{aligned}
& -\mu_{k} \triangleleft v_{i+(k-1)} \text { is defined } \\
& -r_{1}\left(\operatorname{ref}\left(\mu_{k}\right)\right)=r_{2}\left(\operatorname{ref}\left(v_{i+(k-1)}\right)\right)=\operatorname{ref}\left(\mu_{k}\right)^{-} 1 \text {, and }
\end{aligned}
$$

- for all $j$ between $1 \leq j \leq n$ with $j \neq i+(k-1), r_{2}\left(\operatorname{ref}\left(v_{j}\right)\right)=\operatorname{ref}\left(v_{j}\right)^{\frown 2}$

In this case $\bullet\left(\alpha, \beta,\left\langle r_{1}, r_{2}\right\rangle\right)=\left\langle\left[\epsilon_{p}: 1 \leq p \leq n\right]\right\rangle$ where:

$\epsilon_{p}= \begin{cases}\mu_{k} \triangleleft v_{i+(k-1)} & \text { if } i \leq p \leq i+(m-1) \\ \left\langle\operatorname{ref}\left(v_{p}\right)^{-2},\left\langle\operatorname{vd}\left(v_{p}\right), \mathbf{h d}\left(v_{p}\right)\right\rangle, \mathbf{n}\left(v_{p}\right)\right\rangle & \text { else }\end{cases}$

Definition 1.13 Let $\alpha=\left[\mu_{1}, \ldots, \mu_{m}\right]$ be a saturated referent system and $\beta=$ $\left[v_{1}, \ldots, v_{n}\right]$ another referent system. Then $\mu_{1}$ accesses $v_{i}(1 \leq i \leq n)$ iff $(i)$ either $\mu_{1} \triangleleft v_{i}$ or $v_{i} \triangleright \mu_{1}$ is defined, and (ii) there is no $v_{k}$ with $i<k \leq n$ such that $\mu_{1} \triangleleft v_{k}$ or $v_{k} \triangleright \mu_{1}$ is defined

As it is formulated, the merge requires that the first AIS of the saturated referent system access the first AIS from the bottom of the functor referent system for which the left- or rightward merge of AIS is defined. The notion of access can be made dependent on the language, so that for example in some languages the merge requires that the first AIS of the saturated referent system can only access the last AIS of the functor referent system. The rightward merge of argument identification statements and referent systems can be formulated analogously. 